\title{
A influência dos valores fundamentais do cooperativismo para a efetiva gestão democrática das cooperativas: um modelo de gestão próprio para o exercício da responsabilidade social da empresa ${ }^{1}$
}

\author{
Rafael Spadaro de Freitas \\ Aluno da Faculdade de Administração da Pontifícia Universidade Católica de Porto Alegre
}

Sumario: I. Introdução. II. Compreendendo os valores cooperativos. III. Os princípios cooperativos como pauta para a prática dos valores cooperativos. IV. Democracia, equidade e governança democrática. V. Autoajuda e solidarieadade no vértice da gestão democrática: um marco moral de orientação da ordem econômico-cooperativa. VI. A título de conclusão: a preponderância do fator humano como prerrogativa de responsabilidade social no exercício da atividade empresarial. Referências.

Resumo: De acordo com a declaração sobre a identidade cooperativa, emitida pela Aliança Cooperativa Internacional, o Princípio de Gestão Democrática se traduz pela participação ativa dos seus membros na vida e na gestão da cooperativa. Nesse sentido, a Gestão Democrática, deriva da ideia essencial de que cada sócio representa um voto no seio das assembleias. Por isso, busca-se através desse trabalho, examinar a essência da axiologia da cooperação, verificando a efetiva influência dos valores fundamentais do cooperativismo nos processos internos de gestão. O objetivo central é evidenciar a propriedade dos valores de auto ajuda e solidariedade como marco moral de orientação da ordem econômica, relevando o substrato de responsabilidade social no exercício das atividades empresariais. Para isso vai se utilizar o método dedutivo e indutivo de abordagem, com a aplicação de pesquisa direta e indireta.

Palavras chave: Valores cooperativos. Gestão democrática. Responsabilidade social da empresa.

Resumen: De acuerdo a la Declaración sobre la Identidad Cooperativa emitida por la Alianza Cooperativa Internacional, el Principio de Gestión Democrática traduce la participación activa de los miembros en la vida y gestión de la cooperativa. En este sentido, la Gestión Democrática deriva de la idea esencial de que cada socio presenta un voto en el seno de las asambleas. Por

1 Trabalho orientado pelo Professor Doutor José Eduardo de Miranda. 
ello, buscase, por este trabajo, examinar la esencia de la axiología de la cooperación, verificando la efectiva influencia de los valores fundamentales del Cooperativismo en los procesos internos de gestión. El objetivo central es evidenciar la propiedad de los valores de auto ayuda y solidaridad como marco moral de orientación del orden económico, enmarcando el sustrato de responsabilidad social en el ejercicio de las actividades empresariales. Para ello, se va a utilizar el método deductivo-inductivo de abordaje, con empleo de la investigación directa e indirecta.

Palabras clave: Valores cooperativos. Gestión democrática. Responsabilidad social de la empresa.

Abstract: According to the Declaration on Cooperative Identity issued by the International Cooperative Alliance, the Principle of Democratic Management translates members' active participation into the life and management of the cooperative. In this regard, Democratic Management stems from the core idea that each member has one vote in the assemblies. Therefore, this paper aims to examine the essence of the axiology of cooperation, verifying the effective influence of the fundamental values of Cooperativism in internal management processes. The main objective is to demonstrate the ownership of self-help and solidarity values as a guiding moral framework of the economic system, framing the backbone of social responsibility in the course of business activities. To this end, a deductive-inductive approach is used, with direct and indirect research.

Keywords: Cooperative values. Democratic Management. Corporate Social Responsibility. 


\section{Introdução}

Pode-se dizer que na sua essência, o cooperativismo é um sistema ordenador da vida social, não é apenas uma forma de empresa².

O movimento cooperativista percorreu a história de mãos dadas com o homem, como uma corrente que permitiu que as pessoas se aproximassem, baseadas em valores e princípios comuns, para eliminar todas as formas autoritárias de poder, e para permitir que o próprio homem encontrasse os meios necessários para o seu completo desenvolvimento. No âmbito material, social, pessoal e espiritual ${ }^{3}$.

Compreender esses valores e princípios cooperativos é fundamental para que se perceba suas influências no comportamento das sociedades cooperativas. Sob essa perspectiva, esse artigo inicialmente aborda a definição dos valores cooperativos segundo a declaração centenária da Aliança Cooperativa Internacional, para no capítulo seguinte identificar seus reflexos nos princípios cooperativos.

Através uma análise dos estatutos dos Probos Pioneiros de Rochdale que datam de 1844, a partir da Obra de Luz filho de 1953, afim de relacionar as regras que os Pioneiros utilizaram, com os princípios redefinidos pela declaração da $\mathrm{ACl}$ em 1995.

A partir disso, busca-se através dessa pesquisa, relacionar os valores da democracia e da equidade com a governança democrática das cooperativas, sobretudo, quando se evidencia o entendimento de governabilidade das cooperativas.

No quarto capítulo, destaca-se a conexão entre a auto ajuda e a solidariedade, dois valores cooperativos, que juntos operacionalizam a gestão econômico social que configura a natureza diferenciada das cooperativas. Essas, que nascem e se desenvolvem desde uma perspectiva de gestão democrática.

A título de conclusão aborda-se o fator humano como condição existencial da reponsabilidade empresarial no exercício da atividade de empresa. Entende-se que a "empresa convencional» é capaz de agir de forma «não irresponsável», o que não basta para ser responsável socialmente.

Por fim, o estudo caracteriza a responsabilidade social como consequência do compromisso das cooperativas com suas comunidades ${ }^{4}$. A

2 Divar, J. Apud Miranda, José Eduardo: Filosofía Cooperativa: análisis del proceso de conformación del Cooperativismo, Editora Juruá, Curitiba, 2017, p.15.

3 MiRANDA, 2017, p. 15.

4 Charterina, Alejandro Martinez: La cooperativa y su identidad, Editora Dykinson S.L, Madrid, 2016, p. 93. 
ação cooperativa é interpretada como o próprio exercício da responsabilidade social.

\section{Compreendendo os valores cooperativos}

É importante considerar que os valores são presença marcante no comportamento humano ${ }^{5}$, refletindo na forma de agir, pensar e sentir de todas as pessoas ${ }^{6}$. Sob essa perspectiva, pode-se dizer que quando o homem toma uma decisão ou determina suas preferencias, define o que parece mais importante para ele. Nesse caso, se está diante de um valor propriamente dito ${ }^{7}$.

Dessa forma os valores s conformam no cotidiano humano a partir de uma estrutura hierárquica que possibilita diferenciá-los por preferências subjetivas, de maneira que alguns sejam importantes para determinadas pessoas, enquanto outros, para as demais ${ }^{8}$.

No âmbito do Cooperativismo, a propriedade subjetiva dos valores humanos perde sua razão de ser, fazendo com que todos os valores tenham a mesma importância para cada pessoa, e que cada um dos valores faça parte do movimento cooperativista, materializando-se através dos princípios cooperativos, levados a termo pelas Sociedades Cooperativas e pelos Cooperativistas do mundo?.

Neste aspecto, deve-se dizer que Cooperativas surgiram como entidades jurídicas peculiares, nascidas na Europa do século XIX para suprimirem necessidades múltiplas de uma sociedade que sofria os efeitos traumáticos da revolução Industrial ${ }^{10}$. Deste tempo, até esta data, modelos cooperativos distintos se formataram, abrigando-se dentro dos matizes determinados pela Aliança Cooperativa Internacional $(\mathrm{ACl})$, que, no ano de 1988, no congresso realizado em Estocolmo, instaurou um processo sistêmico de debate sobre os valores e princípios afetos à cooperatividade ${ }^{11}$. Este trabalho, minucioso e de ordem

5 Davis. Apud. Miranda, José Eduardo, 2012, p.62.

6 Morales Vallejo. Apud Miranda, José Eduardo: De la crisis de identidad al rescate de la génesis del Cooperativismo, Editora Dyckinson S.L., p. 63.

7 MiRANDA, José Eduardo, 2012, p. 63.

8 Sallinas Ramos. Apud Miranda, 2012, p. 63

9 MiRANDA, 2012, p. 63.

10 Alianza Cooperativa InTernacional: «Declaración de la Alianza Cooperativa Internacional sobre la Identidad Cooperativa aprobada en Manchester», Anuário de Estudios Cooperativos, Lankidetzako Ikaskuntzen Urtekaria, Bilbao, Universidad de Deusto, p. 78

11 Charterina, Alejandro Martinez, 2016, p. 45. 
global, se iniciou com Lars Marcus e continuou pelas mãos de Sven Ake Book ${ }^{12}$.

No ano de 1995, a Declaração da Aliança Cooperativa Internacional sobre a Identidade Cooperativa, reconheceu que:

Las cooperativas están basadas em los valores de auto ayuda, autorresponsabilidad, la democracia, la igualdad, la equidad y la solidaridad. Siguiendo la tradición de sus fundadores, los socios cooperativos hacen suyos, los valores éticos de la honestidad, la transparencia, la responsabilidad y la vocación sociales. ${ }^{13}$

Foi através da Declaração sobre a Identidade Cooperativa, de 1995, que a $\mathrm{ACl}$, ao identificar os valores cooperativos, relacionou elementos essenciais e axiológicos referentes ao comportamento das cooperativas. Sobre este aspecto, pontuou que a autoajuda, a auto responsabilidade, a democracia, a igualdade, a equidade e a solidariedade, foram denominados como valores fundamentais ou operacionais, intrínsecos ao exercício das próprias cooperativas ${ }^{14}$. Por outro lado, a honestidade, a transparência, a responsabilidade e a vocação social, foram classificados como valores éticos, que dizem respeito ao comportamento dos cooperados e dos colaboradores das sociedades cooperativas ${ }^{15}$.

\section{Os valores fundamentais do Cooperativismo}

Conforme as orientações de Ake Book, incorporadas à Declaração sobre a Identidade Cooperativa, da $\mathrm{ACl}$, os valores fundamentais do Cooperativismo se destacam por terem um caráter estrutural que estão vinculados à organização e às atividades cooperativas ${ }^{16}$. Estes, servem para dar um aspecto comum a todas as classes de cooperativas, proporcionando ao Cooperativismo uma uniformidade.

Além disso, pode-se dizer que os valores fundamentais compreendem a essência da identidade cooperativa. Significam as normas de fundo ideológico que devem determinar a maneira de pensar e atuar

12 lbid.

13 I.C.A., Declaración..., o. C., p.17. Apud ChaRTERINA, 2016, p. 81.

14 Alianza CoOperativa InternaCional: "Declaración de la Alianza Cooperativa Internacional sobre la Identidad Cooperativa aprobada en Manchester», Anuário de Estudios Cooperativos, Lankidetzako Ikaskuntzen Urtekaria, Bilbao, Universidad de Deusto, p. 81-83.

$15 \mathrm{lbid}$

16 Ake Book, S. Apud Miranda, 2012, p. 65. 
dos cooperativistas e, por conseguinte, a forma de ação da entidade ${ }^{17}$. Dentro desta perspectiva, os valores fundamentais apresentam as seguintes características:

\section{Auto Responsabilidade}

Refere-se à responsabilidade que cada membro tem diante de sua cooperativa, desde o surgimento e durante sua existência. O presente valor refere-se também ao compromisso que a cooperativa adquire de requerer a cooperação sobre aqueles que não fazem parte da essência da cooperativa, assumindo o compromisso de preservar a independência do sistema.

A declaração da Aliança Cooperativa Internacional ainda revela que a auto responsabilidade representa a forma de atuar da própria cooperativa, assim a organização também assume o compromisso de desenvolver a capacidade de seus membros e desenvolver condições de sustentar a si mesmo sem interferir na liberdade de seus comuns e se mostram determinadas para atuar na busca de soluções para as dificuldades apresentadas pela comunidade ${ }^{18}$.

A auto responsabilidade significa dizer que os sócios se responsabilizam pela vida da cooperativa, pelo seu funcionamento, pela promoção da cooperativa junto a sociedade, e pela garantia de sua independência mediante as outras organizações ${ }^{19}$.

\section{Democracia}

A preponderância do indivíduo sobre o capital, latente na democracia como valor, se caracteriza pela igualdade de direito de voto dos sócios. O parâmetro para medir a participação do cooperado não se dá pela quantidade de capital investido, é destinado o mesmo valor para tomada de decisões para todas as pessoas da cooperativa independentemente de sua participação no capital da empresa20.

17 MiRANDA, 2012, p.65-66.

18 MIRANDA, 2012, p. 67.

19 Charterina, 2016, p. 82.

20 Arnáez Arce, Vega M. ${ }^{\text {a; }}$; AtXabal Rada, Alberto: «La democracia e l'educazione, valori cooperativi per i Giovani». In Arnáez ArCE, Vega M. ${ }^{a}$ (Org.): Difusión de los valores y principios cooperativos entre la juventud, Editora Dykinson S.L, Madrid, 2015, p. 76. 
Entre os diferentes modelos de empresas, apenas as cooperativas submetem os recursos econômicos ao controle democrático ${ }^{21}$. É justamente a democracia que permite a distinção do método empresarial cooperativo, através da participação democrática, de outros métodos que imperam nas estruturas organizadas para o mercado ${ }^{22}$.

La democracia es uno de los valores consustanciales a la naturaleza de las cooperativas, desde una doble dimensión: hacia dentro de la cooperativa, donde la propiedad, el control y la gestión de las cooperativas se lleva a cabo por los socios de manera democrática; y hacia afuera de la cooperativa, donde el socio cooperativista participa en la economía y organiza los factores de producción a través de una empresa basada en la persona y no en el capital ${ }^{23}$.

Nesse sentido, a democracia como valor cooperativo permite diferenciar as cooperativas das outras organizações econômicas, percebe-se que os demais valores cooperativos de maneira implícita ou explícita podem ser assumidos nas empresas capitalistas convencionais, porém a democracia se caracteriza como norma de comportamento e diferencial das cooperativas entre as empresas capitalistas. A democracia está relacionada com dois princípios cooperativos, o princípio da gestão democrática e o princípio da participação econômica ${ }^{24}$.

$\mathrm{Na}$ declaração de 1995 da $\mathrm{ACl}$ a democracia assim como a ajuda mútua são considerados componentes filosóficos essenciais que se destacam em todas as cooperativas ao longo dos tempos ${ }^{25}$.

\section{Autoajuda}

A informação da declaração da $\mathrm{ACl}$, no que diz respeito a autoajuda, parte da ideia do esforço de que cada pessoa deve empreender para atingir seus objetivos. Enquanto valor cooperativo a auto ajuda se manifesta através da ação coletiva e da responsabilidade mútua.

21 Ibid, p. 64.

22 MiRANDA, 2012, p. 68.

23 AtXabal Rada, Alberto. "Las cooperativas, empresas democráticas para los jóvenes». In Arnáez ArCe, Vega M. ${ }^{a}$ (Org.): Difusión de los valores y principios cooperativos entre la juventud, Editora Dykinson S.L, Madrid, 2015, p. 175.

24 Arnáez Arce, Vega M. ${ }^{a}$; Atxabal Rada, Alberto. 2015, p. 82.

25 Charterina, 2016, p. 82. 
Segundo Gomez, citado por Miranda, isso acontece, devido a crença de que a superação individual de cada pessoa só é possível mediante a união com os demais ${ }^{26}$.

Charterina, ainda sobre a auto ajuda releva que se trata do esforço próprio que constitui o caminho o qual cada pessoa pode alcançar seu destino. A autoajuda se faz visível na cooperativa através da ajuda mútua e da auto responsabilidade. Mediante a autoajuda se desenvolve a personalidade dos sócios e dos demais envolvidos, através da educação ${ }^{27}$.

\section{Igualdade}

A igualdade constitui um dos fundamentos do Cooperativismo, e a prática da igualdade é um objetivo constante das cooperativas. O cooperado tem direito a ser escutado, a estar informado e a participar das tomadas de decisão de forma mais igualitária possível28.

Comisso se entende que o fundamento na pessoa humana é a principal característica que serve para distinguir a Sociedade Cooperativa de qualquer outa empresa organizada em benefício do capital. Não é exagero que a igualdade como valor revela uma ideia de justiça, já que nas sociedades cooperativas seus membros devem ser tratados de forma igualitária29.

\section{Equidade}

A equidade se destaca por ser um desafio constante nas cooperativas. De acordo com a declaração da Aliança Cooperativa Internacional, a equidade «es la forma en la que intentan distribuir ganancias ou riqueza em base a la contribuición y no a la especulación» 30 .

Para Preuss, é o «reconhecimento inconsciente da força que cada homem toma emprestado da prática da ajuda mútua; a estreita dependência da felicidade de cada um com a felicidade dos outros, e o sentido de justiça e equidade que conduz ao indivíduo a consi-

\footnotetext{
26 MIRANDA, 2012, p. 66

27 CHARTERINA, 2016, p. 82.

28 Ibid, p. 83.

29 MiRANDA, 2012, p. 69

30 Charterina, 2016, p, 91.
} 
derar os direitos de todos os demais indivíduos como iguais a seus princípios» $^{31}$.

\section{Solidariedade}

Percebendo a dimensão da expressão solidariedade pode-se dizer que sua essência está fortemente ligada a um espírito coletivo. Esse espírito expressa o ponto de conjunção entre o indivíduo e a cooperativa.

Arismendiarreta, escreve que a solidariedade é o segredo para revolucionar toda a vida social. E no mesmo sentido, Aranzadi esclarece que a solidariedade leva os sócios a «procurar não apenas defender a si mesmos e proteger seus próprios interesses, mas também proteger a pessoa e também os interesses de seus associados e sentir que os problemas dos outros merecem ser atendidos da mesma maneira que os seus» ${ }^{32}$.

\section{Os valores éticos do Cooperativismo}

Os valores éticos são assim denominados por estarem impregnados de um aspecto moral. Caracterizam um bom cooperado, porque estão intrinsecamente relacionados às pessoas que trabalham nas cooperativas.

Esses valores podem ser considerados como qualidades pessoais, identificadas com o espírito cooperativo e a cultura cooperativa. Os mesmos se refletem nas relações entre os membros da cooperativa, entre tais membros e a própria entidade e entre as cooperativas e a comunidade em geral ${ }^{33}$.

\section{Honestidade}

Verifica-se a honestidade especialmente quando «una persona honesta se niega a mentir, a embaucar, a robar aun indirectamente. Sus actos se conforman a sus palabras sus palabras se conforman

31 MiRANDA, José Eduardo. «Valores cooperativos y juventud: La axiología cooperativa». In Arnáez ArCe, Vega M. ${ }^{a}$ (Org.): Difusión de los valores y principios cooperativos entre la juventud, Editora Dykinson S.L, Madrid, 2015, p. 157.

32 MirANDA, 2012, p. 71.

33 MiRANDA, 2012, p.72. 
a su pensamiento. Sin la honestidad cualquier otra virtud no vale mucho» ${ }^{34}$, ou seja, a honestidade pode ser considerada a qualidade ética fundamental.

Com a honestidade os outros valores são somados, porém na falta da dela, os outros valores se enfraquecem. A honestidade, tem a capacidade de proteger a organização, no sentido de manter a integridade de seus valores e a legitimidade do comportamento cooperativo.

\section{Transparência}

Como elemento sobremaneiramente ético, a transparência é de certa forma, um modus informativo de todos os signos de interesse dos membros da cooperativa e comunidade. O valor acima citado deve estar envolvido com a franqueza.

Além disso, deve ser exposto tanto o lado positivo como o negativo de sua execução. Isso significa expor problemas, empecilhos, metas e objetivos. Deve-se primar pela «transparência na oferta de informações completas sobre as atividades da entidade, as suas contas, suas relações com terceiros, a perspectiva de futuro da honestidade sobre como lidar com os membros, e estende-se esta forma de agir fora da cooperativa, com os não membros ${ }^{35} »$.

\section{Responsabilidade Social}

Diretamente ligada à honestidade, "a responsabilidade é um componente fundamental para dignidade humana e um elemento inseparável para a colaboração baseada na confiança mútua ${ }^{36}$. 0 referido valor deve ser assumido pelos sócios perante sua cooperativa; os mesmos se tornam responsáveis também por suscitar sua entidade entre as pessoas ao seu redor.

A responsabilidade social é um dos quatro valores éticos, referente ao comportamento humano que foram reconhecidos pela declaração da $\mathrm{ACl}$ em $1995^{37}$.

\footnotetext{
34 Lasserre, G. Apud Miranda, 2012, p. 73.

35 MiRANDA, 2012, p. 73.

36 MiRANDA, 2012, p. 74.

37 ChARTERINA, 2016, p. 85.
} 


\section{Vocação Social}

Este valor encontra-se totalmente ligado ao valor responsabilidade. A Vocação Social se sobressai pela preocupação com os demais. Através de seus membros a organização é capaz de realizar contribuições financeiras e desenvolver o que for necessário para contribuir com as necessidades sentidas pela comunidade e com o desenvolvimento da mesma.

É possível, assim, dizer que «por su constitución básica, las cooperativas son organizaciones propias para las personas que toman la economía por sus propias manos, toman cuenta unos de los otros y procuran caminos que acojan a las partes menos desfavorecidas del entorno social ${ }^{38}$ ». Desse modo, se revela pela preocupação das cooperativas com o seu entorno e com as pessoas do meio onde se encontra inserida.

Se observa através dos conceitos explorados acima, que os valores cooperativos foram largamente explorados por diferentes autores e em diferentes momentos da história do Cooperativismo.

\section{Os princípios cooperativos como pauta para a prática dos valores cooperativos}

Os Princípios Cooperativos são mandamentos que devem ser seguidos pelas cooperativas ${ }^{39}$. E não basta que a Sociedade Cooperativa somente tenha a preocupação em segui-los, mas deve salvaguardar o dever de questioná-los constantemente, para que arrefeça a busca da organização pelo constante desenvolvimento e preservação do espírito cooperativo 40 .

Sob este aspecto, é importante registrar que a ideia do espírito cooperativo remete nossa atenção aos Probos Pioneiros de Rochdale, reconhecidamente os precursores do Cooperativismo modernos, e detentores do arrefecimento do que se pode chamar de axiologia da cooperação, determinante máxima dos princípios cooperativos ${ }^{41}$.

38 AKE BOOK, S Apud MiRAnda, 2012, p. 74.

39 GADEA, Enrique: «Difusión de valores y principios cooperativos entre los jóvenes». In ArnÁEz ArCe, Vega M. ${ }^{a}$ (Org.): Difusión de los valores y principios cooperativos entre la juventud, Editora Dykinson S.L, Madrid, 2015, p.142.

40 A.C.I Apud ChARTERINA, 2016, p. 39.

41 Aranzadi Tellería. Apud Miranda, José Eduardo: Filosofía Cooperativa: análisis del proceso de conformación del Cooperativismo, Editora Juruá, Curitiba, 2017, p. 67. 
Porém a verdade é que antes de Rochdale, essas entidades nasciam com o objetivo de guardar benefícios para a constituição de entidades autônomas, sem praticar a venda efetivamente ${ }^{42}$.

Observa-se que o movimento cooperativista surgiu, durante a Revolução Industrial, como resposta às necessidades impostas pelo capitalismo à classe operária. No ano de 1844 surgiu a então denominada Sociedade Pioneira dos Probos de Rochdale ${ }^{43}$.

Para Luz Filho, no cerne da Sociedade Cooperativa dos Probos Pioneiros de Rochdale encontrava-se o conjunto de regras, reconhecidas como As Normas Básicas dos Pioneiros. As referidas normas constituíam-se como as seguintes:

Vendas ao preço normal de mercado, juros limitados ao capital, distribuição a pro-rata das compras realizadas pelos associados, compra e venda a dinheiro de contado, igualdade de direitos sem levar em consideração a profissão, idade, sexo, etc.; um homem, um voto, reuniões frequentes e periódicas dos associados, contabilidade metódica e controlada, balanços justos e à disposição de todos os associados para exame e crítica ${ }^{44}$.

Além disso, foi devido a conexão ideológica dos Probos Pioneiros, que realizavam um desenvolvimento contínuo da cooperação que se observara uma profunda transformação na organização econômica e social do mundo ${ }^{45}$. Provavelmente os 28 tecelões de Rochdale, 27 homens e 1 mulher, perceberam que sua empresa poderia oferecer ao mundo uma outra conotação moral e social, proveniente do exercício econômico de uma organização baseada em valores e princípios que enalteciam o valor do humano ${ }^{46}$.

O Certo é que os Probos de Rochdale desenvolveram um padrão de comportamento que se codifica em seus estatutos ${ }^{47}$, e que constituem a origem dos princípios, que desde então, integram-se no movimento cooperativo de todo o mundo 48 .

42 MiRANDA, 2017, p. 68.

43 MIRANDA, José Eduardo. "O Cooperativismo como instrumento próprio à inclusão socioeconômica», Tópicos essenciais em gestão, 01ed, Cachoeiro de Itapemirim, Centro Universitário São Camilo, v.2, 2010, p.255-261.

44 FILHo Luz, Fábio: Teoria e prática das sociedades cooperativas, Editora Rio de Janeiro, 1953, p. 70.

45 Ibid, p. 68.

46 Bonner, 1973, p.20. Apud Miranda, 2017, p. 63.

47 LASERre, G. Apud MirAnda, 2017, p. 87.

48 Mladenatz, 1969. Apud Miranda, 2017, p. 88. 
Para Luz Filho, esses princípios trouxeram à ordem econômica um fator moral, que consiste na ajuda mútua e que tem por lema um por todos e todos por um ${ }^{49}$. Para entender a evolução dos princípios cooperativos é importante salientar que Aliança Cooperativa Internacional $(A C I)$, desde sua criação em 1895, vem sendo a autoridade máxima que trata da definição de cooperativas, bem como do desenvolvimento dos princípios que devem servir de base às ações das mesmas.

Atenta ao cenário socioeconômico, a Aliança Cooperativa Internacional foi responsável por elaborar, nos anos de 1937, 1966 e 1995, declarações formais que tinham por objeto os princípios cooperativos, bem como a identidade cooperativa. Estas versões, segundo a $\mathrm{ACl}$, constituíram tentativas de explicar como deveriam ser interpretados os princípios cooperativos no contexto do mundo contemporâneo ${ }^{50}$.

Posteriormente, no Congresso em que celebrou seu centenário, em Manchester, no ano de 1995, a ACl enumerou os seguintes princípios cooperativos: Adesão voluntária e aberta; Gestão Democrática por parte dos sócios; Participação Econômica por parte dos sócios; Autonomia e independência; Educação, Formação e Informação; Cooperação entre as cooperativas; e Interesse pela comunidade ${ }^{51}$.

\section{Democracia, equidade e governança democrática}

A democracia, como valor cooperativo, alimenta dois princípios cooperativos fundamentais, quais sejam: o princípio da gestão democrática e o princípio da participação econômica ${ }^{52}$. Ou seja, a democracia como valor, reflete-se no princípio de gestão democrática quando os sócios ficam sujeitos às responsabilidades, direitos e deveres que uma

49 FILHO LUZ, 1953, p. 25.

50 Alianza CoOperativa InTERnACIONAL: «Declaración de la Alianza Cooperativa Internacional sobre la Identidad Cooperativa aprobada en Manchester», Anuário de Estudios Cooperativos, Lankidetzako Ikaskuntzen Urtekaria, Bilbao, Universidad de Deusto, p. 77 e 78.

51 GADEA, Enrique: «Difusión de valores y principios cooperativos entre los jóvenes». In ArnÁEz ArCe, Vega M. ${ }^{\text {a }(O r g .): ~ D i f u s i o ́ n ~ d e ~ l o s ~ v a l o r e s ~ y ~ p r i n c i p i o s ~ c o o p e r a t i v o s ~ e n t r e ~ l a ~}$ juventud, Editora Dykinson S.L, Madrid, 2015, p. 139.

52 AtXABAl RADA, Alberto. "La democracia e l'educazione, valori cooperativi per i Giovani». In ArnÁez ArCe, Vega M. ${ }^{a}$ (Org.): Difusión de los valores y principios cooperativos entre la juventud, Editora Dykinson S.L, Madrid, 2015, p.184.

CHARTERINA, 2016, p. 83. 
democracia implica. Devendo os cooperados ainda, incluir a percepção mais ampla de que o fomento do espírito da democracia deve ser essencial na gestão das cooperativas.

Na Declaração sobre a Identidade Cooperativa, editada no Congresso de Manchester, em 1995, observa-se que princípio da gestão democrática prenuncia que:

Las cooperativas son organizaciones gestionadas democráticamente por los socios, los cuales participan activamente en la fijación de sus políticas y en la tomada de decisiones. Los hombres e las mujeres elegidos para representar y gestionar las cooperativas son responsables ante los socios. En las cooperativas de primero grado los socios tienen iguales derechos de voto (un socio, un voto). Las cooperativas de otros grados están también organizadas de forma democrática ${ }^{53}$.

Já, com relação ao princípio da participação econômica, a influência da democracia se dá no aspecto da gestão do capital. Na primeira frase da declaração da $\mathrm{ACl}$ de 1995 sobre o terceiro princípio, da participação econômica dos sócios, observa-se na forma da gestão a influência da democracia. "Os sócios contribuem equitativamente com o capital de suas cooperativas e realizam a gestão de forma democrática ${ }^{54} \gg$.

A gestão cooperativa que valorizar e garantir a equidade e a participação efetiva de todos os seus membros, estará fortalecendo a governança democrática e cumprindo os sete princípios do Cooperativismo ${ }^{55}$. É através dessa governança democrática que gera-se um ambiente favorável e positivo para o equilíbrio entre os diferentes fatores sociais de produção, valorizando o alcance dos objetivos globais da cooperativa e do Cooperativismo ${ }^{56}$.

Por essa característica, de organização democrática, é fundamental nas cooperativas que a governança democrática seja promovida e vigiada a partir de seus associados. Se não houver uma adequada governabilidade, não haverá envolvimento e comprometimento da base social. Sem esse compromisso, o risco de ingovernabilidade é grande

53 GADEA, 2015, p. 139.

54 ChARTERINA, 2016, p. 62.

55 BütTEnBender, Pedro Luís: Fundamentos e estrutura do Cooperativismo. - ljuí: Ed. Unijuí, 2009, p. 28. Disponível em: «http://bibliodigital.unijui.edu.br:8080/xmlui/bitstream/handle/123456789/186/Fundamentos\%20e\%20estrutura\%20do\%20Cooperativismo.pdf? sequence=1» Acesso em: 08/09/2017.

56 Ibid. p. 28. 
e inclusive pode pôr em perigo a existência da própria organização cooperativa ${ }^{57}$.

No caso das cooperativas, a governabilidade é a capacidade de inter-relação e equilíbrio entre a Assembleia Geral, o Conselho de Administração, o Conselho Fiscal, as Gerências e o pessoal administrativo e operacional, para valorizar, desenvolver e proteger os interesses de seus associados e da própria organização cooperativa ${ }^{58}$.

As cooperativas são organizações democráticas nas quais os cooperados se agrupam principalmente para satisfazer suas necessidades. Os princípios cooperativos são as diretrizes por meio das quais as cooperativas põem em prática seus valores, os quais estão relacionados à governabilidade ${ }^{59}$.

Para garantir essa governabilidade, como processo democrático, parte-se de valores fundamentais que estabelecem a moral necessária para a boa gestão cooperativa. Este processo somente será válido se levar em conta uma estrutura de governança democrática, sensibilizada e consciente sobre a importância de instituir estas práticas fundamentadas nos valores do Cooperativismo ${ }^{60}$. Só assim, a soma dos votos individuais poderá representar a vontade coletiva.

\section{Autoajuda e solidarieadade no vértice da gestão democrática: um marco moral de orientação da ordem econômico-cooperativa}

Aqui, neste ponto, mister se faz a conexão entre a auto ajuda e a solidariedade, que juntas operacionalizam a gestão econômico social que configura a natureza diferenciadas das cooperativas, que nascem e se desenvolvem desde uma perspectiva de gestão democrática. Essa gestão se destina a satisfação das necessidades econômicas e à promoção social educacional e moral dos membros a ela integrados, e também à própria sociedade em que está inserida61.

Dentro dessa probabilidade, a Sociedade Cooperativa pressupõe a mobilização de uma ação cooperativa fundamentada na solidariedade de homens que almejam além de necessidades materiais (de caráter

57 BütTenBender, Pedro Luís: Fundamentos e estrutura do Cooperativismo. - ljuí: Ed. Unijuí, 2009, p. 26. Disponível em: «http://bibliodigital.unijui.edu.br:8080/xmlui/bitstream/handle/123456789/186/Fundamentos\%20e\%20estrutura\%20do\%20Cooperativismo.pdf? sequence $=1 »$ Acessado em: 08/09/2017.

58 Ibid, p.16.

59 Ibid, p.16

60 Ibid, p. 17

61 Ibid, p. 5. 
econômico), mas anseiam também, promover o progresso, o bem-estar e a transformação moral do Homem.

Sobre esse fator moral, resgata-se sua origem dos estatutos da Cooperativa dos Probos de Rochdale, os quais estabeleceram regras que transcenderam o caráter econômico do funcionamento societário, na medida em que estabeleceram também esse objetivo moral62. Tal fato, além de buscar a melhoria da relação humana entre os indivíduos que viviam em sociedade, procura assentar um valor de decência global capaz de suplantar as diferenças espirituais, ideológicas e culturais, o que resulta na construção de um mundo provido de uma nova moral e um melhor sistema de sociedade ${ }^{63}$.

Quando esse comportamento humano passa a fazer parte da orientação econômica cooperativa percebe-se que o exercício da atividade da cooperativa se caracteriza como a própria responsabilidade social no exercício empresarial.

\section{A título de conclusão: a preponderância do fator humano como prerrogativa de responsabilidade social no exercício da atividade empresarial}

Vale a pena lembrar que a entidade empresarial celebra uma atividade denominada Empresa, que perfaz a produção, à troca, à circulação de bens e/ou serviços, oriunda de uma iniciativa que é exclusiva de homens, destinada a atender às expectativas de outros homens ${ }^{64}$.

Por tais razões, não se pode deixar de reconhecer que a empresa, ao lado de ser uma realidade econômica, é também uma realidade humana. Por sua própria origem, ela não se trata apenas de estoques acumulados, nem de lucros contabilizados, mas consiste formalmente num complexo de atos humanos, dos quais estoques e lucros não são mais do que o resultado. Nem mesmo os espetaculares progressos da automação poderão modificar o fato de que nenhuma tarefa criadora se realiza na vida da empresa sem a vontade e a iniciativa do homem ${ }^{65}$.

62 MiRANDA, 2012, p. 25.

63 MiRANDA, 2012, p. 25.

64 Gonçalves, Ernesto Lima: Responsabilidade social da empresa,1984. Disponível em: «http://www.scielo.br/scielo.php?script=sci_arttext\&pid=S003475901984000400033» Acesso em: 10/09/2017.

65 Ibid. 
No mundo atual uma empresa não pode ser entendida como uma combinação eficiente de fatores produtivos para gerar bens e serviços, mas também a empresa deve desempenhar um importante papel social como portadora de valores e comportamentos que geram em uma sociedade global onde existe uma nova cobrança na dimensão dos valores intangíveis, como confiança e reputação66.

Quando se analisa o exercício das cooperativas como empresa, a partir da sua essência, percebe-se que a responsabilidade social é resultado do compromisso social que a cooperativa tem com suas comunidades, além disso, valores como a vocação social e a preocupação com os demais levam as cooperativas a realizarem investimentos de diversos tipos em seu entorno67.

De qualquer forma, vale a pena enfatizar que não só as cooperativas, mas todas as instituições sociais, a empresa convencional inclusive, funciona na sociedade por meio de um contrato social, explícito ou implícito, pelo qual sua sobrevivência e seu desenvolvimento se fundamentam no cumprimento de objetivos socialmente desejáveis pela sociedade em geral, e também na distribuição de resultados econômicos, sociais ou políticos entre aqueles grupos dos quais se tira a força para existir68.

Porém quando se estuda as sociedades cooperativas, percebe-se que a verdadeira diferença entre a cooperativa e a empresa convencional está na relação entre o capital e o trabalho. Graças a democracia cooperativa, as empresas cooperativas buscam harmonizar a relação entre o capital e o trabalho. Geram a harmonia que concede a primazia ao trabalho sobre o capital, considerando o capital indispensável como instrumento e não como fim em si69.

A empresa «convencional», no momento em que decidi ser nãoirresponsável, adota estratégias para entregar "alguma» responsabilidade para sociedade, passa então a "fazer» a responsabilidade social.

Já no caso das sociedades cooperativas, seu exercício, se caracteriza por «ser» a própria responsabilidade social. Pois, a cooperativa se administra através da gestão democrática enquanto "empresa convencional» é gerida pelo poder do capital.

66 Villasante. Apud, Charterina, 2016, p. 99.

67 ChARTERINA, 2016, p. 85.

68 GONÇALVES, 1984. Disponível em: «http://www.scielo.br/scielo.php?script=sci_ arttext\&pid=S0034-75901984000400033» Acesso em: 10/09/2017.

69 Büttenbender, Pedro Luís, 2009, p. 25 «http://bibliodigital.unijui.edu.br:8080/ xmlui/bitstream/handle/123456789/186/Fundamentos\%20e\%20estrutura\%20do\%20 Cooperativismo.pdf? sequence=1» Acesso em: 15/09/2017. 
Essa diferença essencial, entre a empresa convencional e a Sociedade Cooperativa, soa um tanto desleal, pelo fato de que muitas vezes as empresas convencionais, tiram proveito da irresponsabilidade social, em prol dos aumentos de lucros em suas corporações.

O certo é que, a auto ajuda a auto responsabilidade, a democracia, a igualdade, solidariedade, honestidade, transparência, responsabilidade, vocação social, se apresentam como o fundamento da atuação empresarial cooperativa, e servem de escudo para a concorrência desleal, pois mesmo que a concorrência se mostre intrínseca às práticas de mercado, quando desenvolvida e fundamentada na axiologia da cooperação tende a ser justa, uma vez que a moral cooperativa tem como objetivo a hegemonia do verdadeiro sentido da dignidade, e faz prevalecer o respeito pela pessoa humana ${ }^{70}$.

\section{Referências}

AliAnZA CoOperativa INTERnACIONAL: «Declaración de la Alianza Cooperativa Internacional sobre la Identidad Cooperativa aprobada en Manchester», Anuário de Estudios Cooperativos, Lankidetzako Ikaskuntzen Urtekaria, Bilbao, Universidad de Deusto.

Arnáez ArCe, Vega M. ; AtXAbal RAda, Alberto: «La democracia e l'educazione, valori cooperativi per i Giovani». In ARnÁEZ ARCE, Vega M. ${ }^{a}$ (Org.): Difusión de los valores y principios cooperativos entre la juventud, Editora Dykinson S.L, Madrid, 2015, p. 75-85.

ATXABAL Rada, Alberto. «La democracia e l'educazione, valori cooperativi per i Giovani». In Arnáez ArCe, Vega M. a (Org.): Difusión de los valores y principios cooperativos entre la juventud, Editora Dykinson S.L, Madrid, 2015, p.165-185.

BütTEnBender, Pedro Luís: Fundamentos e estrutura do Cooperativismo. - ljuí: Ed. Unijuí, 2009. Disponível em: «http://bibliodigital.unijui.edu.br:8080/ xmlui/bitstream/handle/123456789/186/Fundamentos\%20e\%20estrutura\%20do\%20Cooperativismo.pdf? sequence=1» Acessado em: 08/09/2017

CharterinA, Alejandro Martinez: La cooperativa y su identidad, Editora Dykinson S.L, Madrid, 2016.

GADEA, Enrique: «Difusión de valores y principios cooperativos entre los jóvenes». In ArnÁEZ ArCe, Vega M. ${ }^{a}$ (Org.): Difusión de los valores y principios cooperativos entre la juventud, Editora Dykinson S.L, Madrid, 2015, p. 135-146.

GonçALVES, Ernesto Lima: Responsabilidade social da empresa,1984. Disponível em: http://www.scielo.br/scielo.php?script=sci_arttext\&pid=S003475901984000400033 Acesso em: 10/09/2017.

70 MIRANDA, 2012, p.127. 
Filho Luz, Fábio: Teoria e prática das sociedades cooperativas, Editora Rio de Janeiro, 1953.

MIRANDA, José Eduardo: Filosofia Cooperativa: analises del processo de conformación del Cooperativismo, Editora Juruá, Curitiba, 2017.

MIRANDA, José Eduardo: Valores cooperativos y juventud: La axiología cooperativa, Editora Dyckinson S.L, 2015.

MIRANDA, José Eduardo: «Valores cooperativos y juventud: La axiología cooperativa». In Arnáez ArCE, Vega M. ${ }^{a}$ (Org.): Difusión de los valores y principios cooperativos entre la juventud, Editora Dykinson S.L, Madrid, 2015, p. 149163.

MIRANDA, José Eduardo: De la crisis de identidad al rescate de la génesis del Cooperativismo, Editora Dyckinson S.L., 2012.

MIRANDA, José Eduardo. "O Cooperativismo como instrumento próprio à inclusão socioeconômica», Tópicos essenciais em gestão, Cachoeiro de Itapemirim. 01ed. Cachoeiro de Itapemirim, Centro Universitário São Camilo, v.2, 2010, p.255-261. 